\title{
FUTURE ENERGY SCENARIOS OF HOUSEHOLD IN BHAKTAPUR DISTRICT
}

\author{
Yogesh Bajracharya \\ Department of Electronics and Communications Engineering, Khwopa Engineering College, Libali-2, Bhaktapur, \\ Nepal
}

\begin{abstract}
Energy plays a pervasive and critically important role in economic and social development. So, energy planning is important area of study. For Bhaktapur district energy plan, the survey was done by using the questionnaire. Total of 91 samples from rural area and 112 samples from urban area were taken to prepare primary database. The total energy demand was $952 \mathrm{TJ}$ in rural area and $458 \mathrm{TJ}$ in urban area in 2013.

LEAP (Long-Range Energy Alternative Planning System) software was used for energy planning. Five scenarios, Business as Usual (BAU), Reference (REF), Accelerated Growth Rate (ACC), and Sustainable Energy for All (SE4ALL) in REF and ACC case scenarios were developed. Total energy demand in 2030 will be 2,748 TJ for BAU, 3,799 TJ for REF and 6,203 TJ for ACC case whereas total demand limits from $766 \mathrm{TJ}$ and 1,241 TJ in SE4ALL scenario in REF and ACC case respectively. Again the total energy demand for 2045 will be 4,945 TJ, 9,104 TJ and 22,592 TJ for BAU, REF and ACC case respectively. Total energy demand for SE4ALL scenario will be $1,807 \mathrm{TJ}$ and 4,381 TJ for REF and ACC case respectively. The GHG reduction up to 2045 by SE4ALL approach is 1.79 million metric tons of $\mathrm{CO}_{2}$ equivalent in $\mathrm{REF}$ and 3.54 million metric tons of $\mathrm{CO}_{2}$ equivalent in ACC Scenario.
\end{abstract}

Keywords: Bhaktapur, LEAP, Energy, scenarios

\section{Introduction}

Energy plays a pervasive and critically important role in economic and social development. The identification and analysis of energy issue, and the development of energy policy options are, therefore, important areas of study by governments, researchers, and the development communities. Integrated Energy Planning means analysis of all energy issues within a unified policy framework in order to arrive a set of national optimal energy solution over long term. One of the most crucial outcomes of Integrated Energy Planning has been energy master plan (Codoni, 1985). Establishing energy database, building economic growth scenario and making energy demand projections are key steps of energy planning.

*Corresponding author: Er. Yogesh Bajracharya

Department of Electronics and Communications Engineering,

Khwopa Engineering College, Libali-2, Bhaktapur, Nepal

Email: bajracharya.yogesh@khec.edu.np

(Received: 2015 July 10 Accepted: 2015 Aug 03)
Bhaktapur district, located in the eastern part of Kathmandu Valley, covers an area of $119 \mathrm{~km}^{2}$ (DDC, 2011). According to CBS (2014), 69\% of total households use Liquefied Petroleum Gas (LPG) and 25\% of total households use firewood as usual sources of cooking. Only 3\% of households use kerosene as usual fuel for cooking. For lighting, $98 \%$ of total households use electricity and $1 \%$ of households use kerosene as usual source of lighting. Biogas and solar photovoltaic are used by less than $1 \%$ as usual source for lighting.

It is needed to know the current situation of the district and to develop energy plan for the sustainable development of the rural as well as urban area of the district.

\section{Research Objective}

- $\quad$ To prepare primary database of energy consumption of Bhaktapur district in 2013. 
- To develop scenarios of energy consumption using LEAP software up to 2045.

\section{Literature Review}

Since the energy crisis of the 1970's, rural household energy consumption has become a common focus for analyses in the Least Developed Countries (LDCs). Rural energy consumption in LDCs constitutes the majority of total national energy use. According to UNDP and World Bank estimates based on investigations in 15 LDCs, household energy consumption accounts for 30-95\% [compared with $25-30 \%$ in developed countries ] of total energy use. The poorer the country, the greater the consumption of biomass. In Nepal, per capita total primary energy supply is just $15 \mathrm{GJ} /$ year, which is far less than world's average of $77 \mathrm{GJ} /$ year (IEA, 2010). Electricity consumption per capita is $104 \mathrm{KWh}$ (UNESCAP, 2012). The total primary energy consumption in year 2008/09 was estimated to be about $401 \mathrm{PJ}$ (WECS, 2011).

\subsection{Long-range Energy Alternatives Planning (LEAP)}

LEAP is an accounting framework simulation modeling tool developed at the Stockholm Environment Institute. It is widely used in developing countries as a modeling tool for integrated resource planning and greenhouse gas (GHG) mitigation assessments. More than 85 signatories of the United Nations Framework Convention on Climate Change (UNFCCC) also use it to report their GHG inventories (Heaps, 2008). In LEAP, the forecasting of energy demand is the result of two variables, (i) Activity levels and (ii) Energy intensity.

The number of households can be used to represent the activity level. When it comes to energy intensity, the data requirements are much more challenging, particularly so if a detailed analysis is desired. With statistical information at hand, historical energy intensity values are calculated as the result of total energy consumption of the household sector divided by the chosen activity level.

\section{Research Methodology}

\subsection{Selection of sampling area}

Total population of the Bhaktapur district of 2011 was 303,027 (CBS, 2011). Population living in municipalities of the district was 168,152 i.e $55 \%$ of total and rest of the population i.e. $45 \%$ live in V.D.C.s of Bhaktapur district. Average household size was 4.15 which was smaller than national household size of 4.9 (NPCS, 2011).

Madhyapur Thimi municipality was selected as urban area for sampling. Chhaling VDC was selected among sixteen VDCs because of its geographical diversity. It touches the urban area of Bhaktapur municipality and extends up to hills in the north. Thus, it represents the overall geography of Bhaktapur district.

\subsection{Questionnaire}

The questionnaire was prepared as per World Bank format, based on "Energy Policies and Multitopic Household Surveys Guidelines for Questionnaire Design in Living Standards Measurement Studies".

\subsection{Determination of Sample Size:}

The sample size was calculated by using the formula:

$\mathrm{SS}=\mathrm{Z}^{2}(\mathrm{p})(1-\mathrm{p}) / \mathrm{c}^{2}$ (Kothari, 2004), Where,

$\mathrm{Z}=\mathrm{Z}$ value

$\mathrm{p}=$ percentage picking a choice,

$\mathrm{c}=$ confidence interval, expressed as decimal

And, for finite population,

New $\mathrm{SS}=\mathrm{SS} /(1+(\mathrm{SS}-1) /$ population $)$

After choosing $95 \%$ of confidence level and $10 \%$ confidence interval, 91 data was collected from total 9 wards of Chhaling V.D.C. Since 55 percent of populations of district live in municipality total sample from municipality was

$\mathrm{S}=91 * 55 / 45=112$.

There are total of 17 wards in Madhyapur Thimi Municipality. Sample was taken from each ward with respect to population percentage.

\subsection{Data Analysis and Energy planning.}

The obtained data were entered in SPSS (Statistical Package for Social Science) software. The program is used for data documentation and data analysis. Basically to get descriptive statistics such as frequencies, mean, deviation etc. the SPSS software is used. For analysis of energy pattern and future energy demand scenario the LEAP software is used. 


\section{Energy Survey and Data Analysis}

Establishing energy database is the first step of the overall energy planning process. The obtained results are divided into six major categories which are lighting, cooking, electric appliances, space heating, space cooling and refrigeration.

\subsection{Percentage of Household Access in Different Energy Consuming Activity}

The survey shows that the penetration of energy consuming appliances is higher in urban households than in rural households as shown in figure below:

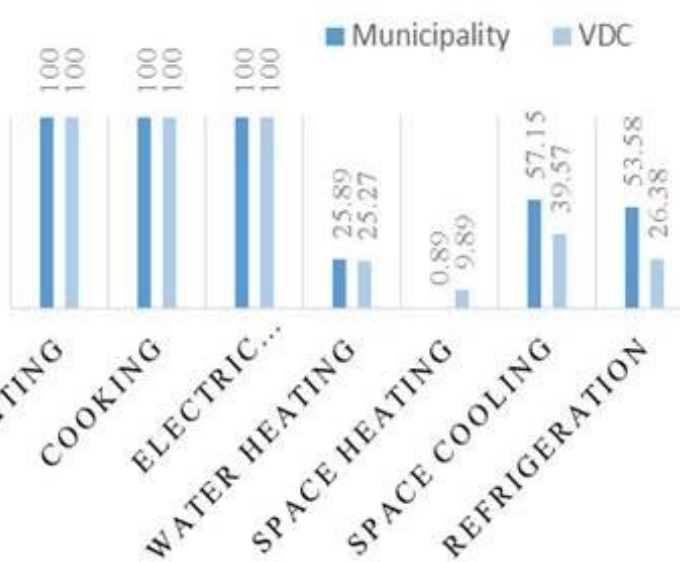

Fig 1 Percentage of household access in different energy consuming activity

\section{Space Heating}

Only $0.98 \%$ of municipality households use electric heater for space heating and $9.89 \%$ of VDC households consume energy for space heating. The rural households use locally available firewood for space heating purpose.

\section{Lighting}

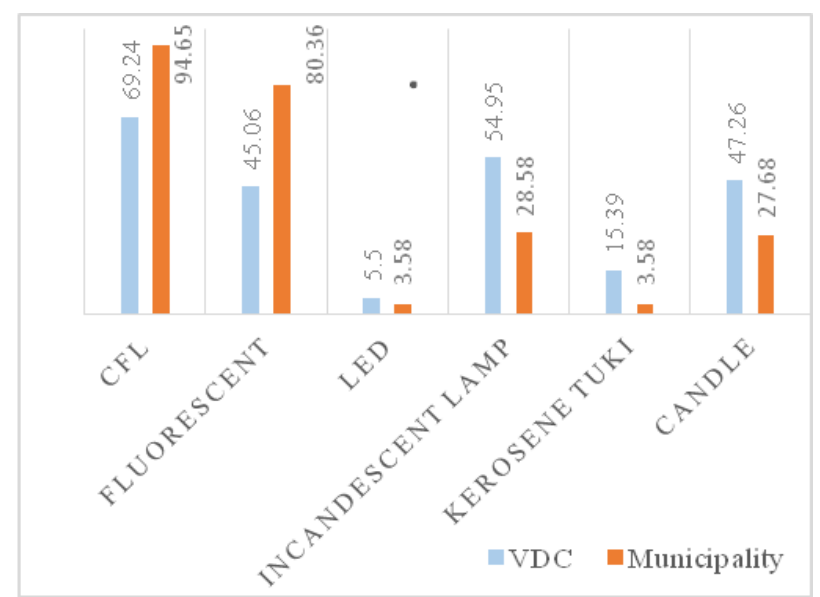

Fig 2 Percentage of household with different lighting appliances.

\section{Cooking}

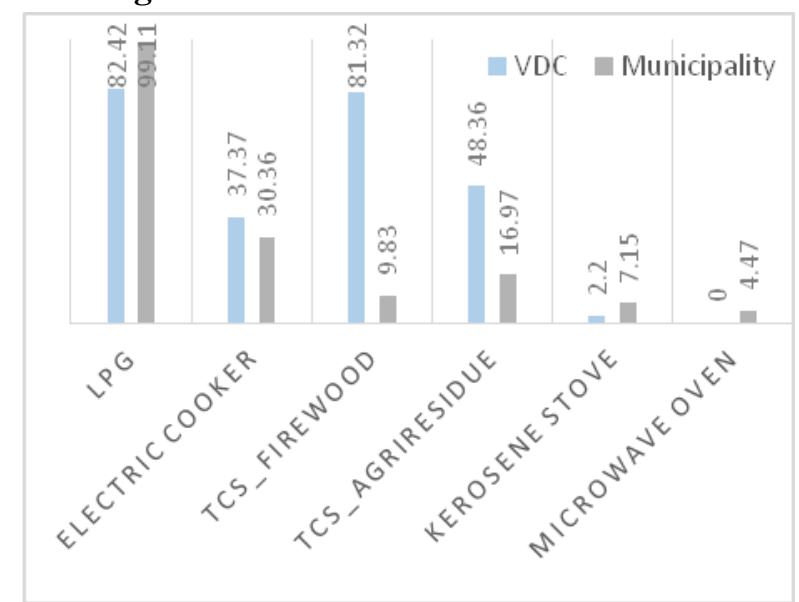

Fig 3 Percentage of households using different types of cooking devices.

\section{Electric appliances}

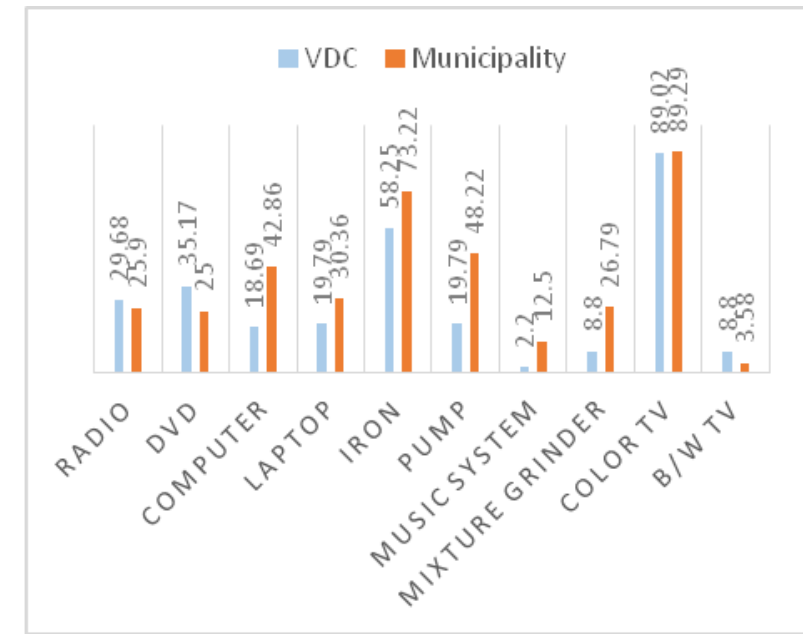

Fig 4 Percentage of household with different electric appliances

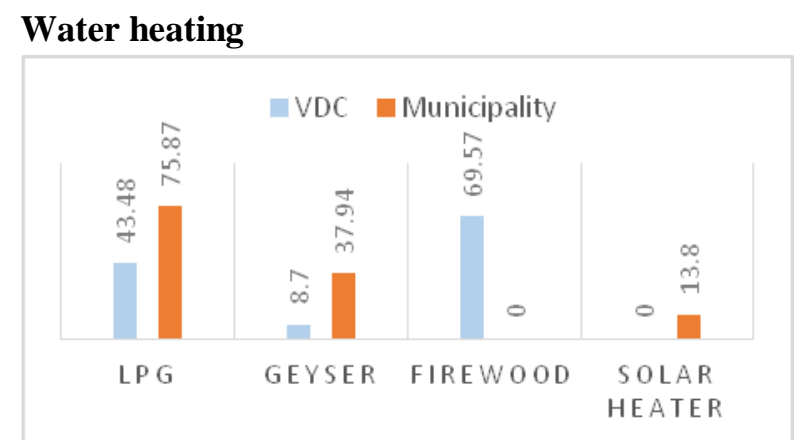

Fig 5 Percentage of households using different fuels for water heating. 


\section{Space Heating}

Only $0.98 \%$ of municipality households use electric heater for space heating and $9.89 \%$ of VDC households consume energy for space heating. The rural households use locally available firewood for space heating purpose.

\section{Space cooling}

Total of $39.57 \%$ of households of VDC use fan for space cooling in summer season and $51.57 \%$ of total households in municipality use fan for space cooling purpose. No air conditioning system is found to be installed in household purpose.

\section{Refrigeration}

The use of refrigerator in municipality is higher than VDC, i.e., $53.58 \%$ of households in municipality has refrigerator whereas only $26.38 \%$ of households in VDC has refrigerator in their houses.

\subsection{Total energy consumption}

Total energy consumption is calculated as the product of activity level and annual energy intensity(energy used per unit of activity).

\section{Cooking}

The average number days that LPG cylinder last normally in household is 82.83 days in VDC and 47.39 days in municipality. The average operation of electric cooker is 0.94 hours per day in VDC and 1.13 hours per day in municipality. The firewood consumption is $3.77 \mathrm{~kg}$ per day in VDC and in municipality is $1.97 \mathrm{~kg}$ per day. The total agricultural residue consumed is $2.58 \mathrm{~kg}$ per day per household in VDC and $1.87 \mathrm{~kg}$ per day per household in municipality

Table 1 Final energy intensity consumed in cooking (GJe per household per year)

\begin{tabular}{|l|l|l|}
\hline Appliances & Urban & Rural \\
\hline LPG Stove & 5.1 & 2.9 \\
\hline Rice Cooker & 0.7 & 0.6 \\
\hline TCS_Firewood & 11.2 & 21.3 \\
\hline TCS_Agricultural & 10.6 & 14.6 \\
\hline ICS & 0 & 0 \\
\hline
\end{tabular}

(Source: Calculation from data of field survey)

\section{Lighting}

The final energy intensity of different electric appliances for lighting is given by the product of number of appliances, wattage rating and total hours of operation.

Table 2 Final energy intensity consumed in lighting (MJe per household per year)

\begin{tabular}{|l|l|l|}
\hline Appliances & Urban & Rural \\
\hline Incandescent lamp & 258.5 & 561.7 \\
\hline Fluorescent & 750.8 & 376 \\
\hline CFL & 213.9 & 195.6 \\
\hline LED & 19.6 & 65.7 \\
\hline Kerosene Tuki & 108.7 & 108.7 \\
\hline
\end{tabular}

(Source: Calculation from data of field survey)

\section{Electric appliances}

Total energy consumption in a year is obtained by the product of total operating hours and wattage rating of respective electric appliances.

Table 3 Final energy intensity consumed by electrical appliances (MJe/HH/year)

\begin{tabular}{|l|l|l|}
\hline Appliances & Urban & Rural \\
\hline Radio & 32.1 & 31.3 \\
\hline DVD & 2.2 & 2.2 \\
\hline Computer & 676.7 & 632 \\
\hline Laptop & 191.3 & 177.8 \\
\hline Iron & 99.2 & 118.1 \\
\hline Water pump & 630.3 & 631.4 \\
\hline
\end{tabular}

(Source: Calculation from data of field survey)

\section{Space cooling}

Fan is used only in summer season for cooling purpose. The average electricity consumption is 36 KWh per year.

\section{Refrigeration}

Refrigerator with no energy star consumes more than $500 \mathrm{KWh}$ per year whereas five-star energy efficient consumes less than $250 \mathrm{KWh}$ per year. Also, as the age of refrigerator increases, the energy consumption also increases. Thus, we suppose average existing refrigerator consumes $450 \mathrm{KWh}$ per year. 


\subsection{Energy Balance for current account.}

After obtaining the activity level and energy intensity, the data was used as the input data in LEAP software. According to cumulative loss report, 2070/071, NEA Thimi and Bhaktapur Distribution Center, the transmission and distribution loss of Thimi Distribution center was $13 \%$ and that of Bhaktapur Distribution center was $41 \%$. The total energy demand in 2013 was 1410.2 TJ. The energy balance of Bhaktapur district that is obtained from LEAP software for the year 2013 is shown in table below (Table 4)

Table 4 Energy balance for Bhaktapur for base year 2013.

\begin{tabular}{|l|r|r|r|r|r|}
\hline Scenario: Reference, Year: 2013 (TJ) & \multicolumn{5}{|l|}{} \\
\hline & Renewables & Biomass & Electricity & \multicolumn{1}{l|}{ Products } & \multicolumn{1}{l|}{ Total } \\
\hline Production & 6.5 & 915.9 & - & - & 922.4 \\
\hline Imports & - & - & 260.7 & 299.3 & 559.9 \\
\hline Exports & - & - & - & - & - \\
\hline Total Primary Supply & 6.5 & 915.9 & 260.7 & 299.3 & 1482.3 \\
\hline Electricity Generation & -6.5 & - & 6.5 & - & - \\
\hline Transmission and & & & & & \\
Distribution & - & - & -72.1 & - & -72.1 \\
\hline Total Transformation & -6.5 & - & -65.7 & - & -72.1 \\
\hline Household & - & 915.9 & 195 & 299.3 & 1410.2 \\
\hline Urban & - & 117.3 & 131.1 & 210.5 & 458.9 \\
\hline Rural & - & 798.6 & 64 & 88.8 & 951.3 \\
\hline Total Demand & - & 915.9 & 195 & 299.3 & 1.410 \\
\hline Unmet Requirements & - & 0 & 0 & - & 0 \\
\hline
\end{tabular}

(Source: Study estimate from LEAP software by Author)

\section{Energy Scenario of Bhaktapur District}

Energy demand forecasting is an essential component for energy planning, formulating strategies and recommending energy policies. GDP growth rate is assumed in three different scenarios.

\subsection{Business as Usual Case Scenario (BAU)}

Economic growths of past Decade from 2003/04 to 2012/13 are 4.4, 3.2, 3.7, 2.8, 5.8, 3.9, 4.3, 3.8, 4.5, and 3.6 respectively. (MoF, 2013)

For BAU Case Scenario, the GDP growth rate is assumed to be $4 \%$, the average value of last decade.

\subsection{Reference Case Scenario (REF)}

The GDP growth rate is assumed as the expected
GDP growth rate by three year plan published by National Planning Commission. The Approach Paper of 13th Plan (2013/14-2015/16) has been drafted with a long term vision of attaining Millennium Development Goals as per commitment of Nepal and to upgrade the country from the Least Developed Country (LDC) to a developing nation within the next decade. According to this approach paper, the GDP is expected to be $6 \%$ for this plan (NPC, 2013).

\subsection{Accelerated Growth Case Scenario (ACC)}

Being a member state of the United Nations and belonging to the LDC category, Nepal has targeted to graduate from the LDC status by 2022 . The target economic growth rate of Nepal from 2013/14 to $2021 / 22$ is follows: $5.6,6.5,7.5,9.2,10.3,11,11.2$, 10.6, and 9.2 (NPC, 2014)

So, for this scenario, the economic growth rate is assumed as its targeted growth rate and after 2022, the economic growth rate is assumed to be the average of last decade i.e. 9.2\%. However, economic growth rate of 2013/14 was $5.2 \%$ (MoF, 2014).

\subsection{Sustainable Energy for All scenario}

"Sustainable Energy for All" is launched as a global initiative by UN Secretary-General Ban Ki-moon in September 2011, is vision that would mobilize action from all sectors of society for making it reality by 2030 in support of three interlinked objectives:

1. Providing universal access to modern energy services;

2. Doubling the global rate of improvement in energy efficiency; and

3. Doubling the share of renewable energy in the global energy mix.

This scenario is developed under Reference scenario and Accelerated Growth Rate Scenario. In this scenario, it is assumed that there will be total electrification for household purpose in 2030.

\section{Energy Demand Projections.}

To project the energy demand, different scenarios based on economic growth rate is developed. 


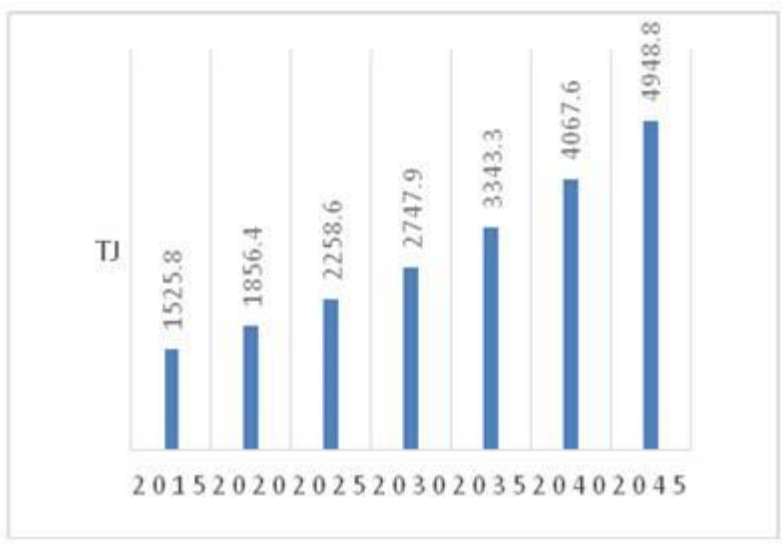

Fig 6 Energy Demand Scenario for Business as Usual Case.

\subsection{Energy Demand for BAU Case}

The total fuel consumption in BAU scenario increases $4 \%$ per year. With no technological intervention the energy mix remains constant. The total fuel consumption of BAU scenario reaches to 4,949 TJ in 2045 as shown in figure below (Fig 6):

\subsection{Energy Demand for REF Case}

In REF scenario, the energy mix remains constant. The total energy demand of REF case scenario increases $6 \%$ annually. The total fuel demand will reach up to $9,104 \mathrm{TJ}$ in 2045 .

The energy demand scenario for REF case scenario is shown in figure below (Fig 7):

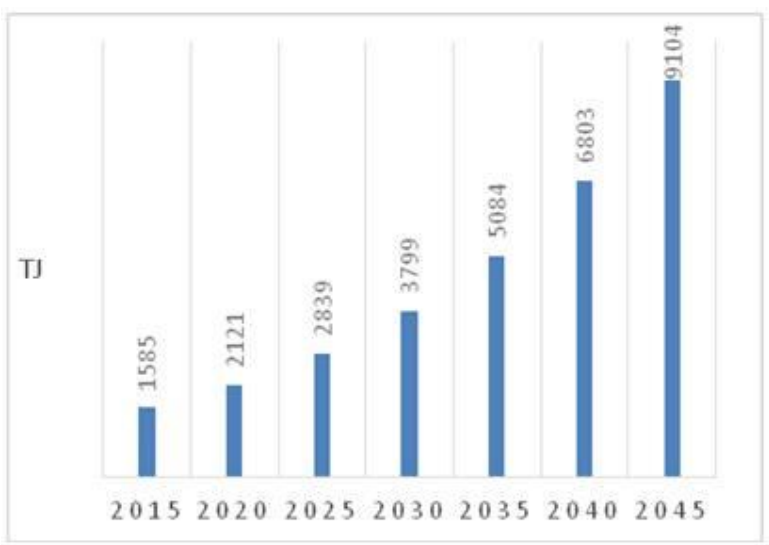

Fig 7 Energy Demand Scenario for Reference Case

\subsection{Energy Demand for REF (SE4ALL) Case}

Sustainable development is not possible without sustainable energy. Also, Green House Gas (GHG) emission reduction is necessary by use of efficient and cleaner technologies. In this scenario, different assumptions are made for sustainable development. The average transmission and distribution loss of $27 \%$ in Bhaktapur district will be reduced to $20 \%$ in 2015 and 10\% in 2030 (Nakarmi, 2010). The fuel consumption for this scenario for different areas is described below:

In present context, major source of cooking is LPG in urban area and firewood and agricultural residue in rural area. If all the cooking is electrified in 2030, the total energy will be in decreasing trend up to 2030 and reaches $190 \mathrm{TJ}$ and will increase up to 457 $\mathrm{TJ}$ in 2045 in urban area. The fuel consumption for cooking will decrease up to142 TJ in 2030 and then it will increases and reach $340 \mathrm{TJ}$ in 2045 in rural area.

If all lighting appliances are replaced by energy efficient LED lamp by 2030, electricity consumption for lighting will be decreased to $2.1 \mathrm{TJ}$ in urban and $11.3 \mathrm{TJ}$ in rural in 2030 and then increased to 5.1 and $13.8 \mathrm{TJ}$ in urban and rural respectively in 2045 .

We assume that all CRT television will be replaced by energy efficient LED television by 2045, and the computer will be gradually replaced by laptop. The fuel consumption of electric appliances in REF (SE4ALL) scenario will reach $33401 \mathrm{TJ}$ and 228.9 TJ for urban and rural respectively.

Other assumptions made are water heating will be done by solar water heater by 2030 and space heating and space cooling will also be electrified by 2030. It is assumed that all existing refrigerator will be replaced by energy efficient refrigerator by 2030 .

\section{Overall Energy Demand Scenario of Sustainable Energy for All in Reference Case Scenario, REF (SE4ALL)}

The consumption of firewood, biomass, LPG and petroleum products will gradually decrease and become zero in 2030. As the traditional fuel is replaced by efficient fuel i.e. electricity, the total energy demand in 2030 will become 766 TJ which is less than current consumption of fuel, i.e. 1,400 TJ in base year 2013. After that, due to the economic growth and increase of fuel, the total energy consumption will also increase and will reach up to $1,807 \mathrm{TJ}$ in 2045 . 


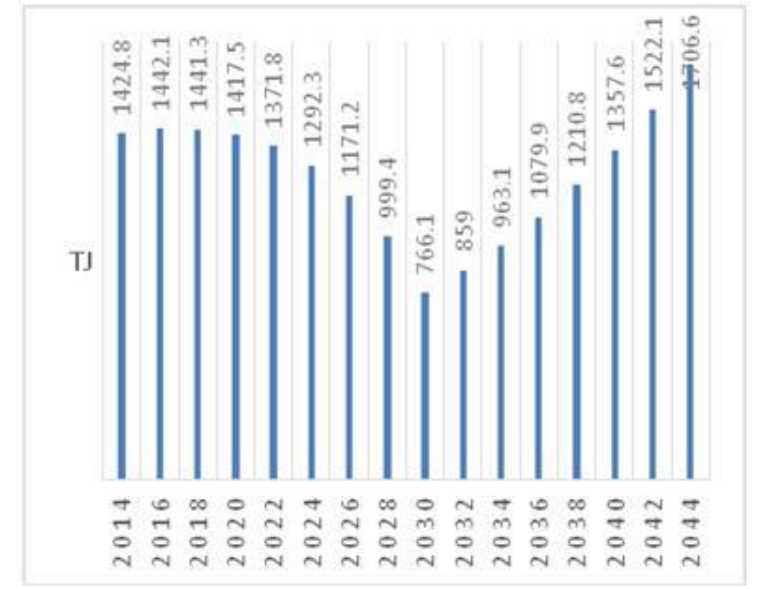

Fig 8 Energy Demand Scenario for REF (SE4ALL) case

\subsection{Energy Demand for Accelerated Growth Rate Case (ACC)}

For ACC case, no technological intervention is assumed. Thus, in this scenario the fuel consumed by different areas is growing rapidly. The growth rate reaches up to $11.2 \%$ in 2019/2020. The total energy demand of firewood in 2045 will reach 9,825 TJ. The energy demand for Accelerated Growth Rate Case (ACC) is shown in figure below (Fig: 9):

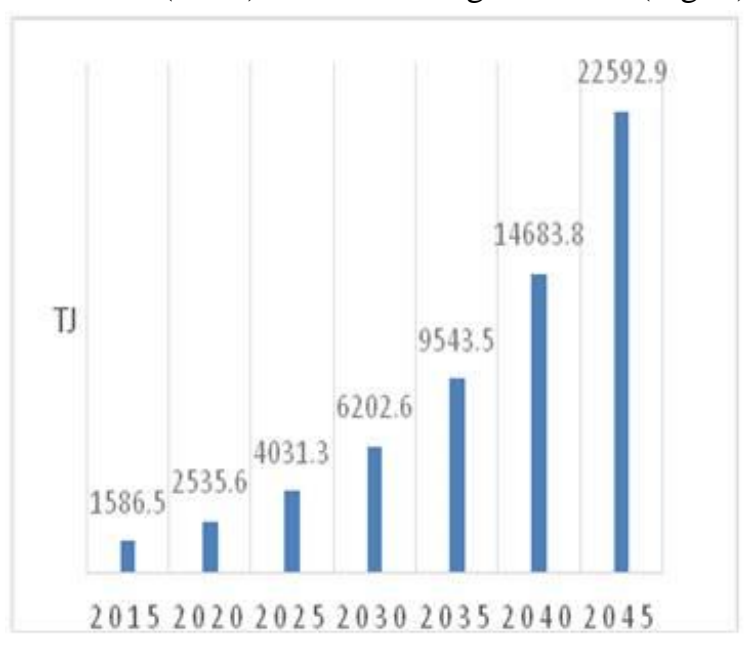

Fig 9 Energy demand for ACC case

\subsection{Overall Energy Demand Scenario of ACC (SE4ALL) Case}

In this scenario, the assumptions made are similar to previous REF (SE4ALL) case. The energy demand will increase up to $1,729 \mathrm{TJ}$ in 2023 and after that year, the demand goes decreasing up to 1,241 $\mathrm{TJ}$ in 2030. After 2030, the energy demand will be increasing. This is due to the fact that rapid demand of energy in this scenario is compensated by the intervention of newer and more efficient fuel. In
2030, all traditional fuel will be replaced by electricity and the demand of electricity then onwards increases rapidly as per GDP. The energy demand for sustainable energy for all case in accelerated growth rate scenario is shown in figure below (Fig 10)

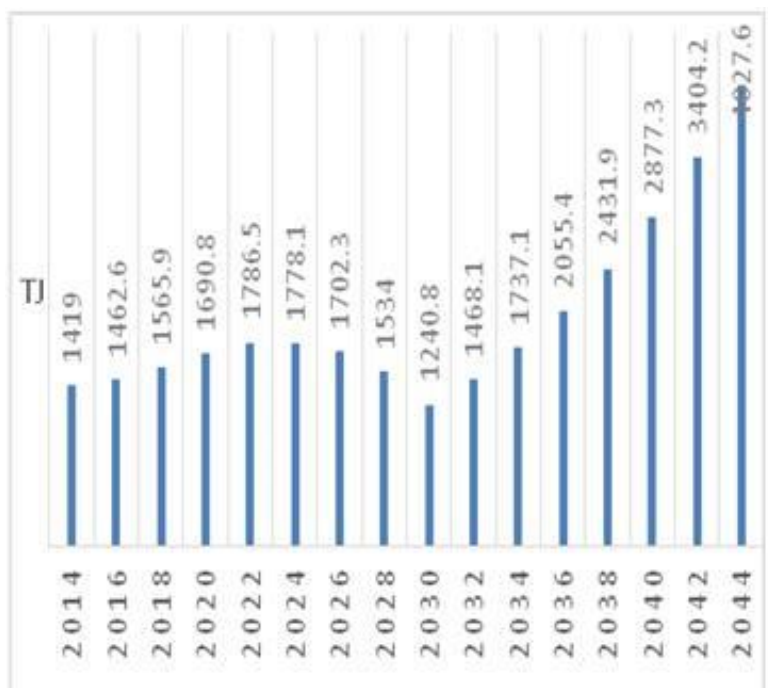

Fig 10 Energy demand for ACC (SE4ALL) case.

\section{Green House Gas Emissions}

The total GHG emission up to 2045 is 1.41 million metric tons of $\mathrm{CO}_{2}$ equivalent in $\mathrm{BAU}, 2.07$ million metric tons of $\mathrm{CO}_{2}$ equivalent in REF and 3.86 million metric tons of $\mathrm{CO}_{2}$ equivalent in ACC. When sustainable development approach is taken, the total GHG emissions reduce to 0.27 million metric tons of $\mathrm{CO}_{2}$ equivalent in SE4ALL_REF and 0.32 million metric tons of $\mathrm{CO}_{2}$ equivalent in

Fig 10. Energy demand for ACC (SE4ALL) case.

SE4ALL_ACC. Therefore total GHG reduction in SE4ALL approach is 1.79 million metric tons of $\mathrm{CO}_{2}$ equivalent in REF and 3.54 million metric tons of $\mathrm{CO}_{2}$ equivalent in ACC Scenario.

\section{Conclusion}

Household energy is one of the important sectors of consumption of energy in the country. Some of the important conclusion drawn from the research work are as follows:

Total energy demand of reference year 2013 is 1,410.8 TJ. Final energy demand will be 2,0748TJ, 3,799TJ and 6,202TJ for BAU, REF and ACC case scenario. When sustainable development approach 
is taken, the total energy demand will be 766TJ and 1,240 TJ in 2030. Final energy demand will reach 4.9PJ, 9.1 PJ and 22.6 PJ for BAU, REF and AC case scenario in 2045. For sustainable development, final energy will be 1.8 PJ and 4.4 PJ for REF and ACC case scenario. The GHG reduction by SE4ALL approach is 1.79 million metric tons of $\mathrm{CO}_{2}$ equivalent in REF and 3.54 million metric tons of $\mathrm{CO}_{2}$ equivalent in ACC Scenario.

\section{References}

[1] Codoni, R., Park, H. and Ramani, K.V, 1985, “Integrated Energy Planning”, APDC, Kula Lumpur.

[2] DDC, 2011, "Bhaktapur district profile- 2067", District Development Committee, Bhaktapur.

[3] CBS, 2014, "National Population and Housing Census 2011 (Village Development Committee/Municipality), Bhaktapur", Central Bureau of Statistics, Government of Nepal, Thapathali, Kathmandu.

[4] IEA, 2010. "Key World Energy Statistics 2010", International Energy Agency
[5] UNESAP, 2012, "Statistical Yearbook for Asia and the Pacific 2012", United Nations-Economic and Social Commission for Asia and Pacific.

[6] WECS, 2011, "Draft National Energy Strategy of Nepal", Water and Energy Commission Secretariat, Kathmandu Nepal

[7] Heaps, C., (2008), "An introduction to LEAP". Retrieved November 2013, from http://www.energycommunity.org/documents/LEAPIntr o.pdf

[8] CBS, 2011, "National census 2068", Central Bureau of Statistics, Government of Nepal, Thapathali, Kathmandu.

[9] NPCS, "Nepal living standards survey 2010/11, Statistical report volume one", Central Bureau Of Statistics, National Planning Commission Secretariat, Government of Nepal

[10] Kothari C.R., 2004, "Research methodology, Methods and techniques", Second Revised Edition, New Age Techno Press.

[11] Nakarmi, A., 2010, "Modelling for energy planning and policy analysis for Nepal", Joint TERI-ETSAP workshop. 